\section{LUPUS SCIENCE\& MEDICINE}

\title{
Identification of clinical and serological factors during induction treatment of lupus nephritis that are associated with renal outcome
}

\author{
Maria Dall'Era, ${ }^{1}$ Victoria Levesque, ${ }^{2}$ Neil Solomons, ${ }^{3}$ Matt Truman, ${ }^{4}$ David Wofsy ${ }^{5}$
}

To cite: Dall'Era M, Levesque V, Solomons N, et al. Identification of clinical and serological factors during induction treatment of lupus nephritis that are associated with renal outcome. Lupus Science \& Medicine 2015;2: e000089. doi:10.1136/lupus2015-000089

Received 13 February 2015 Revised 24 March 2015 Accepted 21 April 2015

\section{CrossMark}

\author{
${ }^{1}$ Division of Rheumatology, \\ UCSF, San Francisco, \\ California, USA \\ ${ }^{2}$ Vifor Pharma, Victoria, \\ British Columbia, Canada \\ ${ }^{3}$ Aurinia Pharma, Victoria, \\ British Columbia, Canada \\ ${ }^{4}$ Truman Statistical Services, \\ Sydney, Australia \\ ${ }^{5}$ Division of Rheumatology, \\ UCSF, San Francisco, \\ California, USA
}

Correspondence to Dr Maria Dall'Era; maria.dallera@ucsf.edu

\section{ABSTRACT}

Objective: To identify factors associated with clinical outcome in patients with lupus nephritis.

Methods: Data from the Aspreva Lupus Management Study (ALMS) were analysed. Using multivariate analysis, we assessed the prognostic value of demographic, clinical, laboratory and histopathological features on the frequency of either complete remission (CR) or treatment failure (TF) during the maintenance phase.

Results: Among the 370 subjects who entered the trial (complete population), non-Hispanic ethnicity was associated with a higher likelihood of CR (OR=2.0). Several factors were independently associated with a greater likelihood of TF, including: (1) anti-doublestranded DNA (anti-dsDNA) at trial entry (OR=12.7), (2) failure to reduce anti-dsDNA within 8 weeks $(O R=2.9)$ and (3) failure to reduce urine protein:creatinine ratio $(\mathrm{UP} / \mathrm{C})$ by $\geq 25 \%$ within 8 weeks $(\mathrm{OR}=2.6)$. Among the 227 subjects who entered the maintenance phase (maintenance population), baseline estimated glomerular filtration rate (eGFR) $\geq 90 \mathrm{~mL} / \mathrm{min} / 1.73 \mathrm{~m}^{2}$ was associated with a greater likelihood of $\mathrm{CR}(\mathrm{OR}=2.0)$, and $U P / C>1$ at the end of induction was associated with a lower likelihood of $\mathrm{CR}(\mathrm{OR}=0.3)$. Induction treatment with intravenous cyclophosphamide (IVC) was associated with a lower likelihood of TF $(O R=0.5)$, while lack of treatment with antimalarials $(O R=2.4)$, failure to reduce anti-dsDNA during the first 8 weeks of induction $(O R=3.5)$, failure to reduce UP/C during the first 8 weeks of induction $(O R=2.1)$ and anti-dsDNA positivity at the end of induction $(\mathrm{OR}=8.3)$ were independently associated with a greater likelihood of TF.

Conclusions: This analysis demonstrates that levels of anti-dsDNA and UP/C during induction treatment are independently associated with renal outcome over the ensuing 3 years in both the complete and maintenance populations. Ethnicity is associated with renal outcome in just the complete population, and eGFR, induction treatment and treatment with antimalarials are associated with renal outcome in just the maintenance population.

\section{INTRODUCTION}

Lupus nephritis continues to be a major source of morbidity and mortality in patients with systemic lupus erythematosus, with

\section{KEY MESSAGES}

- The complexity and morbidity associated with lupus nephritis underscore the importance of determining factors that predict response to therapy.

- Among patients who continued into the maintenance phase of ALMS, baseline eGFR $>90 \mathrm{ml} / \mathrm{min} /$ $1.73 \mathrm{~m}^{2}$ and $\mathrm{UP} / \mathrm{C}<1$ at the end of induction were independently associated with complete remission during the maintenance phase. Induction treatment with intravenous cyclophosphamide was associated with a lower likelihood of treatment failure.

- Among patients who continued into the maintenance phase of ALMS, lack of treatment with anti-malarials, failure to reduce anti-dsDNA or UP/C within 8 weeks of induction, and positive anti-dsDNA at the end of induction were independently associated with treatment failure.

$10 \%-15 \%$ of patients ultimately progressing to end-stage renal disease. ${ }^{1}$ The variability of treatment regimens and time to treatment response along with the heterogeneous and unpredictable course of lupus nephritis underscore the importance of identifying factors that are associated with response to therapy. We previously identified several clinical and serological characteristics that were associated with response to treatment during the 6-month induction phase of the Aspreva Lupus Management Study (ALMS), a randomised controlled trial of 370 patients with class III-V lupus nephritis. ${ }^{2}$ Although renal response at 6 months is an important endpoint, there is a greater clinical need to determine factors that are associated with long-term renal outcomes. ALMS provides an excellent opportunity to begin to address this issue because the study included a 36-month maintenance phase that followed completion of induction therapy. The analyses presented here examine factors that are associated with clinical outcome for all 370 
subjects who entered ALMS (complete population) as well as for the 227 subjects who continued into the maintenance phase (maintenance population). Analyses were performed separately within these two populations because the patients comprising the two populations were very distinct. Only those patients who achieved a renal response at the end of the induction phase were eligible to enter into the maintenance phase of the trial.

\section{PATIENTS AND METHODS}

Study design

ALMS was a randomised, open-label, multinational, multicentre trial of mycophenolate mofetil (MMF) versus pulse intravenous cyclophosphamide (IVC) for induction therapy of lupus nephritis followed by a randomised, double-blind comparison of MMF versus azathioprine (AZA) for maintenance therapy in those patients who responded to induction. ${ }^{3}$ Importantly, subjects who did not meet criteria for renal response at week 24 were withdrawn from the trial. The institutional review boards at each participating centre approved the study. All of the study subjects gave written informed consent prior to randomisation into the study.

Details of the study design have been previously published. ${ }^{4}$ In brief, eligible patients had biopsy-proven class III-V lupus nephritis within 6 months of study entry and laboratory tests consistent with active nephritis, including evidence of an active urine sediment, proteinuria $\geq 1 \mathrm{~g} /$ day or elevated serum creatinine $(>1.3 \mathrm{mg} / \mathrm{dL})$. Patients with class III or V lupus nephritis were required to have higher levels of proteinuria ( $\geq 2 \mathrm{~g}$ /day) or serum creatinine $>1.3 \mathrm{mg} / \mathrm{dL}$. Only patients who met prespecified criteria for a complete or partial renal response after 24 weeks of induction therapy and were adjudicated as responders by the clinical endpoints committee (CEC) were advanced into the maintenance phase of the trial.

\section{ALMS outcome measures}

Renal response at 6 months of the induction phase was defined as a decrease in the urine protein:creatinine ratio $(\mathrm{UP} / \mathrm{C})$ on a $24 \mathrm{~h}$ collection to $<3$ in patients with baseline nephrotic-range proteinuria $(\mathrm{UP} / \mathrm{C}>3)$ or by $\geq 50 \%$ in patients with subnephrotic-range proteinuria and stabilisation or improvement in serum creatinine levels. Complete renal remission in ALMS was defined as $\mathrm{UP} / \mathrm{C} \leq 500 \mathrm{mg}$ on a $24 \mathrm{~h}$ collection, an inactive urine sediment and serum creatinine level within $25 \%$ of baseline. Complete renal remission was assessed at any time during the maintenance phase. Patients might have achieved complete remission at the end induction and remained in complete remission or, alternatively, achieved a partial remission at the end of induction and later developed a complete remission. Renal response (complete or partial) was required for entry into the maintenance phase of the trial. The primary outcome measure in the maintenance phase was the time to treatment failure (TF), defined by any of the following criteria as adjudicated by a CEC: (1) death, (2) endstage renal disease, (3) sustained doubling of serum creatinine, (4) renal flare, (5) requirement for rescue therapy. The definitions of renal flare were:

- Proteinuric renal flare. doubling of the UP/C and proteinuria $(\geq 1 \mathrm{~g}$ of protein per $24 \mathrm{~h}$ in patients with urinary protein clearance of $\leq 0.5 \mathrm{~g}$ per $24 \mathrm{~h}$ at the end of induction and $\geq 2 \mathrm{~g}$ per $24 \mathrm{~h}$ in patients with urinary protein clearance of $>0.5 \mathrm{~g}$ per $24 \mathrm{~h}$ at the end of induction).

- Nephritic renal flare: increase of $25 \%$ or more in the lowest serum creatinine level during the period from screening to the end of induction plus one or more of the following findings: simultaneous doubling of urinary protein clearance, reaching a minimum of $2 \mathrm{~g}$ per $24 \mathrm{~h}$ (or the UP/C equivalent); new or increased haematuria ( $\geq 5$ red cells per high-power field or $\geq 2+$ on a dipstick test for blood); or the appearance of cellular casts.

\section{Baseline factors associated with renal outcome}

We analysed several baseline (start of induction) demographic, clinical, serological and histopathological factors to determine whether they were associated with $\mathrm{TF}$ or complete renal remission during the maintenance phase. These characteristics included race, ethnicity, age, biopsy class, duration of lupus nephritis, estimated glomerular filtration rate (eGFR), anti-double-stranded DNA (anti-dsDNA) antibody level, C3 and C4 complement levels, $24 \mathrm{~h} \mathrm{UP} / \mathrm{C}$, induction treatment (IVC or MMF) and use of antimalarials or statins. We examined these factors separately within the complete population and within the maintenance population. The characteristics of the complete and maintenance populations are described in table 1 .

\section{Changes in factors during the induction phase}

In addition to the baseline variables described above, we sought to determine if changes in biological factors during the induction phase were associated with TF or complete renal remission during the maintenance phase. We examined reduction in proteinuria, reduction in anti-dsDNA levels and improvement in C3 and C4 from baseline to week 8 in both the complete and maintenance populations. We chose the time point of week 8 for two reasons: (1) we wanted to understand whether changes in biological factors very early in the induction period were associated with renal response during the maintenance phase, and (2) we wanted to be consistent with the methodology of our original manuscript in which we demonstrated that normalisation of complement by week 8 and/or reduction in proteinuria by week 8 were associated with renal response at the end of induction at week 24. In the analysis of the maintenance population, we also assessed anti-dsDNA positivity, eGFR, proteinuria and complement levels at the end of induction. Normalisation of complement was defined as a C3 
Table 1 Demographic and disease characteristics (populations: complete ITT population and maintenance population)

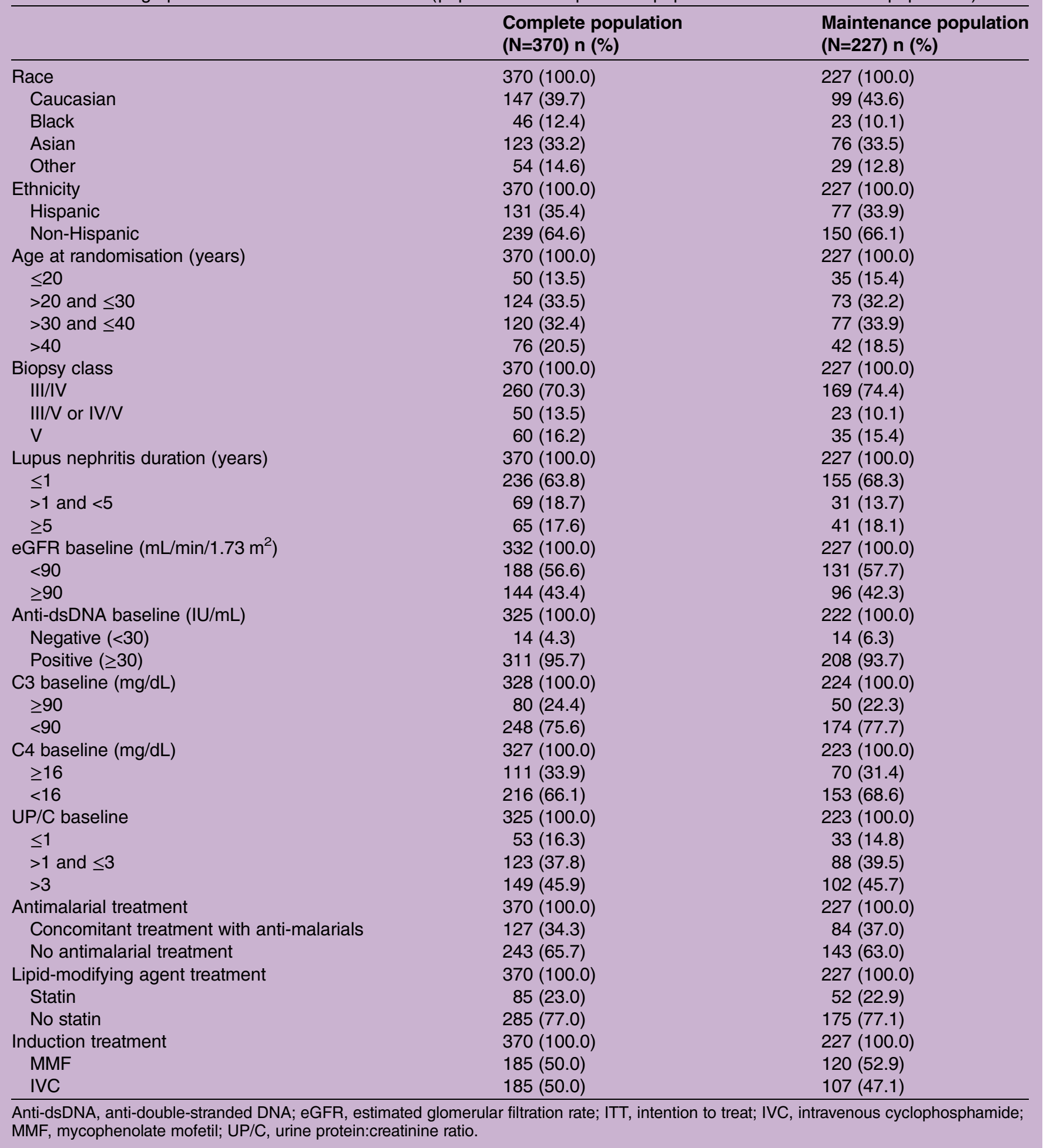

level of $<90 \mathrm{mg} / \mathrm{dL}$ or a C4 level of $<16 \mathrm{mg} / \mathrm{dL}$ at baseline with the corresponding week 8 value being $\geq 90 \mathrm{mg} / \mathrm{dL}$ (C3) or $\geq 16 \mathrm{mg} / \mathrm{dL}$ (C4). Reduction in proteinuria was defined as a decrease of $\geq 25 \%$. Reduction in anti-dsDNA was defined as a decline to $\leq 60 \mathrm{IU} / \mathrm{mL}$ for subjects with baseline anti-dsDNA of $>200 \mathrm{IU} / \mathrm{mL}$ or to $\leq 30 \mathrm{IU} / \mathrm{mL}$ for subjects with baseline anti-dsDNA of $>30 \mathrm{IU} / \mathrm{mL}$ and $\leq 200 \mathrm{IU} / \mathrm{mL}$.
Statistical methods

The number and percentage of successes and failures were calculated for each level of each covariate for both treatment outcome variables along with univariate ORs, 95\% CIs and $p$ values. These univariate analyses were performed on all the patients randomised into the ALMS (complete population, $\mathrm{n}=370$ ) and for all the patients who finished the induction phase and entered the 
maintenance phase (maintenance population, $\mathrm{n}=227$ ). For the complete population analyses $(n=370)$, patients not randomised into the maintenance phase were assumed to have a treatment outcome of either TF or non-complete remission as appropriate. Factors showing a significant $(\mathrm{p}<0.05)$ association with treatment outcome are discussed in the Results section.

In order to ascertain the extent to which the various factors were independent of each other, a multivariate logistic regression analysis was conducted. To avoid multicollinearity, a correlation matrix was produced for all variables; groups of covariates that were correlated with each other (Pearson's rank correlation >0.7) were inspected, and only the variable most highly correlated with treatment outcome was put forward into the multivariate analysis.

The multivariate analysis was repeated for each population and each treatment outcome, with three methods of selecting variables used: forward selection, backward elimination and stepwise. Different methods were used to check for consistency, with the stepwise procedure being the primary method. Variables were entered into the multivariate model (forward and stepwise selection methods only) if they were significant at the 0.1 level and left the model (backward and stepwise selection methods only) if they became non-significant at that level.

In the analysis of the complete population, the following variables were available for selection into the multivariate model for TF and complete remission: all demographic and disease characteristic variables, $\mathrm{UP} / \mathrm{C}$ reduction at week 8 , anti-dsDNA reduction at week 8 , C3 normalisation at week $8, \mathrm{C} 4$ normalisation at week 8 and normalisation of both $\mathrm{C} 3$ and $\mathrm{C} 4$ by week 8 . For the analysis of the maintenance population, the following additional variables, measured at the end of the induction phase, were used in the multivariate analysis: UP/C, anti-dsDNA, C3, C4 and eGFR. Following correlation analysis, the normalisation of both C3 and $\mathrm{C} 4$ by week 8 was omitted from the maintenance population multivariate analyses.

Presence of covariates in the various multivariate models indicates that they are independent predictors of treatment outcome. While covariates remain in the models if they show significance at the $\mathrm{p}<0.1$ level, only those with $\mathrm{p}<0.05$ are discussed in the Results section.

\section{RESULTS}

The ALMS demonstrated that there was no difference in efficacy between MMF and IVC for the induction treatment of lupus nephritis at 24 weeks. ${ }^{3}$ However, during the subsequent 36-month maintenance phase, MMF was shown to be superior to AZA in preventing TF in patients who initially responded to induction therapy. ${ }^{5}$

Tables 2 and 3 show the results of the univariate analyses for the baseline characteristics examined. Table 4 shows the results of the univariate analyses of clinical changes that occurred during induction therapy. Table 5 shows the results of the multivariate analysis.
Association of baseline factors with complete renal remission or TF

Several baseline factors at the start of induction were independently associated with complete renal remission or TF during the maintenance phase (table 5). In the complete population of 370 patients, non-Hispanic ethnicity was the only baseline characteristic associated with complete renal remission. A total of $40 \%$ of nonHispanic patients achieved renal remission compared with $32 \%$ of Hispanic patients (OR 2.0, 95\% CI 1.2 to 3.3, $\mathrm{p}=0.0061$ ). Also among the complete population, the presence of anti-dsDNA was the only baseline factor that was independently associated with TF. Only 7\% (1) 14) of patients who were negative for anti-dsDNA at the start of induction became TFs during maintenance therapy, compared with $50 \%$ of patients who were anti-dsDNA positive (OR 12.7, 95\% CI 1.6 to 101.9, $\mathrm{p}=0.0167$ ). Within the maintenance population of 227 patients, baseline eGFR $\geq 90 \mathrm{~mL} / \mathrm{min} / 1.73 \mathrm{~m}^{2}$ was independently associated with complete renal remission ( $65 \%$ vs $58 \%$, OR $2.0,95 \%$ CI 1.0 to $3.8, \mathrm{p}=0.0407$ ). Also within the maintenance population, induction treatment with IVC and treatment with antimalarials were independently associated with reduced risk of TF. A total of $19.6 \%$ of patients induced with IVC were TFs during the maintenance phase, compared with $28.3 \%$ of patients induced with MMF (OR $0.5,95 \%$ CI 0.2 to $1.0, \mathrm{p}=0.05$ ). Patients who were not treated with antimalarial agents during induction were more likely to be TFs during the maintenance period (26\% vs $21 \%$, OR $2.4,95 \%$ CI 1.1 to $5.1, \mathrm{p}=0.0209$ ).

None of the other baseline characteristics examined was independently associated with either complete renal remission or TF during the maintenance phase. These characteristics included race, age, duration of lupus nephritis, biopsy class, C3 concentration, C4 concentration, UP/C and statin use. Although not achieving statistical significance in the multivariate model, biopsy class was associated with complete remission and $\mathrm{TF}$ in the univariate analysis. Among the complete population of 370 patients (table 2), mixed proliferative and membranous biopsy were negatively associated with complete renal remission in that only $22 \%$ of patients with mixed class biopsy achieved a complete renal remission versus $40 \%$ of the pure class III or IV patients (OR $0.4,95 \%$ CI 0.2 to $0.8, \mathrm{p}=0.0161$ ). A total of $70 \%$ of patients with biopsies containing mixed proliferative and membranous features (III/V or IV/V) became TFs, compared with $50 \%$ of patients with pure class III or IV (OR 2.4, 95\% CI 1.2 to 4.5, $\mathrm{p}=0.0095)$. Lastly, in the univariate analysis of the maintenance population, patients with baseline age $>40$ years were less likely to be TFs during the maintenance period. A total of $14 \%$ of patients $>40$ years versus $40 \%$ of patients $\leq 20$ years were TFs during maintenance (OR $0.3,95 \%$ CI 0.1 to $0.7, \mathrm{p}=0.0133$ ). These comparisons did not achieve statistical significance in the multivariate analysis. 
Table 2 Univariate baseline parameters associated with renal outcome (population: complete population $(n=370)$ )

\begin{tabular}{|c|c|c|c|c|c|c|}
\hline & \multicolumn{3}{|c|}{ Treatment failure } & \multicolumn{3}{|c|}{ Complete renal remission } \\
\hline & n (\%) & OR $(95 \% \mathrm{Cl})$ & p Value & $\mathrm{n}(\%)$ & OR (95\% Cl) & p Value \\
\hline \multicolumn{7}{|l|}{ Race } \\
\hline Caucasian (ref) & $75(51.0)$ & & & $59(40.1)$ & & \\
\hline Black & $31(67.4)$ & $2.0(1.0$ to 4.0$)$ & 0.0538 & $13(28.3)$ & 0.6 (0.3 to 1.2$)$ & 0.1487 \\
\hline Asian & $62(50.4)$ & $1.0(0.6$ to 1.6$)$ & 0.9200 & $49(39.8)$ & $1.0(0.6$ to 1.6$)$ & 0.9602 \\
\hline Other & $30(55.6)$ & $1.2(0.6$ to 2.2$)$ & 0.5685 & $17(31.5)$ & 0.7 (0.4 to 1.3$)$ & 0.2634 \\
\hline \multicolumn{7}{|l|}{ Ethnicity } \\
\hline Hispanic (ref) & $78(59.5)$ & & & $42(32.1)$ & & \\
\hline Non-Hispanic & $120(50.2)$ & $0.7(0.4$ to 1.1$)$ & 0.0858 & $96(40.2)$ & 1.4 (0.9 to 2.2$)$ & 0.1238 \\
\hline \multicolumn{7}{|c|}{ Age at randomisation (years) } \\
\hline$\leq 20$ (ref) & $29(58.0)$ & & & $20(40.0)$ & & \\
\hline$>20$ and $\leq 30$ & $69(55.6)$ & $0.9(0.5$ to 1.8$)$ & 0.7769 & $38(30.6)$ & 0.7 (0.3 to 1.3$)$ & 0.2376 \\
\hline$>30$ and $\leq 40$ & $60(50.0)$ & $0.7(0.4$ to 1.4$)$ & 0.3421 & $51(42.5)$ & 1.1 (0.6 to 2.2$)$ & 0.7633 \\
\hline$>40$ & $40(52.6)$ & $0.8(0.4$ to 1.7$)$ & 0.5539 & 29 (38.2) & $0.9(0.4$ to 1.9$)$ & 0.8356 \\
\hline \multicolumn{7}{|l|}{ Biopsy class } \\
\hline III/IV (ref) & $129(49.6)$ & & & $105(40.4)$ & & \\
\hline III/V or IV/V & $35(70.0)$ & $2.4(1.2$ to 4.5$)$ & 0.0095 & $11(22.0)$ & 0.4 (0.2 to 0.8$)$ & 0.0161 \\
\hline V & $34(56.7)$ & $1.3(0.8$ to 2.3$)$ & 0.3256 & $22(36.7)$ & $0.9(0.5$ to 1.5$)$ & 0.5959 \\
\hline \multicolumn{7}{|c|}{ Lupus nephritis duration (years) } \\
\hline$\leq 1$ (ref) & $119(50.4)$ & & & 95 (40.3) & & \\
\hline$>1$ and $<5$ & $44(63.8)$ & $1.7(1.0$ to 3.0$)$ & 0.0521 & $19(27.5)$ & $0.6(0.3$ to 1.0$)$ & 0.0567 \\
\hline$\geq 5$ & $35(53.8)$ & $1.1(0.7$ to 2.0$)$ & 0.6251 & $24(36.9)$ & $0.9(0.5$ to 1.5$)$ & 0.6268 \\
\hline \multicolumn{7}{|c|}{ eGFR baseline $\left(\mathrm{mL} / \mathrm{min} / 1.73 \mathrm{~m}^{2}\right)$} \\
\hline$<90$ (ref) & $88(46.8)$ & & & $76(40.4)$ & & \\
\hline$\geq 90$ & $72(50.0)$ & $1.1(0.7$ to 1.8$)$ & 0.5642 & $62(43.1)$ & $1.1(0.7$ to 1.7$)$ & 0.6299 \\
\hline \multicolumn{7}{|c|}{ Anti-dsDNA baseline (IU/mL) } \\
\hline Negative $(<30)$ (ref) & $1(7.1)$ & & & $8(57.1)$ & & \\
\hline Positive $(\geq 30)$ & $157(50.5)$ & $13.3(1.7$ to 103$)$ & 0.0133 & $128(41.2)$ & 0.5 (0.2 to 1.5$)$ & 0.2427 \\
\hline \multicolumn{7}{|l|}{ C3 baseline (mg/dL) } \\
\hline$\geq 90$ (ref) & $43(53.8)$ & & & $32(40.0)$ & & \\
\hline$<90$ & $115(46.4)$ & 0.7 (0.4 to 1.2$)$ & 0.2517 & $106(42.7)$ & $1.1(0.7$ to 1.9$)$ & 0.6658 \\
\hline \multicolumn{7}{|l|}{ C4 baseline (mg/dL) } \\
\hline$\geq 16$ (ref) & $53(47.7)$ & & & $45(40.5)$ & & \\
\hline$<16$ & $104(48.1)$ & $1.0(0.6$ to 1.6$)$ & 0.9453 & $92(42.6)$ & $1.1(0.7$ to 1.7$)$ & 0.7224 \\
\hline \multicolumn{7}{|l|}{ UP/C baseline } \\
\hline$\leq 1$ (ref) & $27(50.9)$ & & & $23(43.4)$ & & \\
\hline$>1$ and $\leq 3$ & $59(48.0)$ & $0.9(0.5$ to 1.7$)$ & 0.7168 & $59(48.0)$ & $1.2(0.6$ to 2.3$)$ & 0.5772 \\
\hline$>3$ & $70(47.0)$ & $0.9(0.5$ to 1.6$)$ & 0.6198 & $54(36.2)$ & $0.7(0.4$ to 1.4$)$ & 0.3578 \\
\hline \multicolumn{7}{|c|}{ Antimalarial treatment concomitantly during induction } \\
\hline Antimalarial (ref) & $61(48.0)$ & & & $56(44.1)$ & & \\
\hline No antimalarial & $137(56.4)$ & $1.4(0.9$ to 2.2$)$ & 0.1270 & $82(33.7)$ & $0.6(0.4$ to 1.0$)$ & 0.0513 \\
\hline \multicolumn{7}{|c|}{ Lipid-modifying agent treatment concomitantly during induction } \\
\hline Statin (ref) & $47(55.3)$ & & & $33(38.8)$ & & \\
\hline No statin & $151(53.0)$ & $0.9(0.6$ to 1.5$)$ & 0.7083 & $105(36.8)$ & $0.9(0.6$ to 1.5$)$ & 0.7403 \\
\hline \multicolumn{7}{|l|}{ Induction treatment } \\
\hline MMF (ref) & 99 (53.5) & & & $72(38.9)$ & & \\
\hline IVC & 99 (53.5) & $1.0(0.7$ to 1.5$)$ & $>0.9999$ & $66(35.7)$ & 0.9 (0.6 to 1.3$)$ & 0.5190 \\
\hline
\end{tabular}

Percentages show the proportion of TFs or complete remitters within the applicable covariate category.

Ref: reference category for ORs.

ORs $>1$ imply more TF or complete remission in comparison category than in reference category.

Anti-dsDNA, anti-double-stranded DNA; eGFR, estimated glomerular filtration rate; IVC, intravenous cyclophosphamide; MMF, mycophenolate mofetil; TF, treatment failure; UP/C, urine protein:creatinine ratio.

Changes in biological parameters during the induction phase and association with renal outcome in the maintenance phase Changes in anti-dsDNA

Failure to reduce anti-dsDNA by week 8 of induction therapy was associated with TF during the maintenance phase in the multivariate analysis of both the complete and maintenance populations (table 5). Among patients in the complete population who did not have an early reduction in anti-dsDNA by week $8,50 \%$ developed TF compared with $27 \%$ who did have an early reduction in 
Table 3 Univariate baseline parameters associated with renal outcome (population: maintenance population $(\mathrm{n}=227)$ )

\begin{tabular}{|c|c|c|c|c|c|c|}
\hline & \multicolumn{3}{|c|}{ Treatment failure } & \multicolumn{3}{|c|}{ Complete renal remission } \\
\hline & $\mathrm{n}(\%)$ & OR (95\% Cl) & p Value & n (\%) & OR (95\% Cl) & p Value \\
\hline \multicolumn{7}{|l|}{ Race } \\
\hline Caucasian (ref) & 27 (27.3) & & & $59(59.6)$ & & \\
\hline Black & $8(34.8)$ & $1.4(0.5$ to 3.7$)$ & 0.4745 & $13(56.5)$ & $0.9(0.4$ to 2.2$)$ & 0.7872 \\
\hline Asian & 15 (19.7) & 0.7 (0.3 to 1.3$)$ & 0.2490 & 49 (64.5) & $1.2(0.7$ to 2.3$)$ & 0.5108 \\
\hline Other & $5(17.2)$ & $0.6(0.2$ to 1.6$)$ & 0.2772 & 17 (58.6) & $1.0(0.4$ to 2.2$)$ & 0.9251 \\
\hline \multicolumn{7}{|l|}{ Ethnicity } \\
\hline Hispanic (ref) & $24(31.2)$ & & & $42(54.5)$ & & \\
\hline Non-Hispanic & $31(20.7)$ & $0.6(0.3$ to 1.1$)$ & 0.0821 & $96(64.0)$ & $1.5(0.8$ to 2.6$)$ & 0.1681 \\
\hline \multicolumn{7}{|c|}{ Age at randomisation (years) } \\
\hline$\leq 20$ (ref) & $14(40.0)$ & & & $20(57.1)$ & & \\
\hline$>20$ and $\leq 30$ & $18(24.7)$ & 0.5 (0.2 to 1.2$)$ & 0.1051 & $38(52.1)$ & $0.8(0.4$ to 1.8$)$ & 0.6199 \\
\hline$>30$ and $\leq 40$ & $17(22.1)$ & $0.4(0.2$ to 1.0$)$ & 0.0524 & $51(66.2)$ & $1.5(0.6$ to 3.3$)$ & 0.3557 \\
\hline$>40$ & $6(14.3)$ & $0.3(0.1$ to 0.7$)$ & 0.0133 & $29(69.0)$ & $1.7(0.7$ to 4.3$)$ & 0.2812 \\
\hline \multicolumn{7}{|l|}{ Biopsy class } \\
\hline III/IV (ref) & $38(22.5)$ & & & $105(62.1)$ & & \\
\hline III/V or IV/V & $8(34.8)$ & $1.8(0.7$ to 4.7$)$ & 0.1998 & $11(47.8)$ & $0.6(0.2$ to 1.3$)$ & 0.1924 \\
\hline V & $9(25.7)$ & $1.2(0.5$ to 2.8$)$ & 0.6799 & $22(62.9)$ & $1.0(0.5$ to 2.2$)$ & 0.9356 \\
\hline \multicolumn{7}{|c|}{ Lupus nephritis duration (years) } \\
\hline$\leq 1$ (ref) & $38(24.5)$ & & & $95(61.3)$ & & \\
\hline$>1$ and $<5$ & 6 (19.4) & 0.7 (0.3 to 1.9$)$ & 0.5383 & 19 (61.3) & $1.0(0.5$ to 2.2$)$ & $>0.9999$ \\
\hline$\geq 5$ & $11(26.8)$ & $1.1(0.5$ to 2.5$)$ & 0.7611 & $24(58.5)$ & $0.9(0.4$ to 1.8$)$ & 0.7482 \\
\hline \multicolumn{7}{|c|}{ eGFR baseline $\left(\mathrm{mL} / \mathrm{min} / 1.73 \mathrm{~m}^{2}\right)$} \\
\hline$<90$ (ref) & $31(23.7)$ & & & $76(58.0)$ & & \\
\hline$\geq 90$ & $24(25.0)$ & 1.1 (0.6 to 2.0$)$ & 0.8165 & $62(64.6)$ & 1.3 (0.8 to 2.3 ) & 0.3171 \\
\hline \multicolumn{7}{|c|}{ Anti-dsDNA baseline (IU/mL) } \\
\hline Negative $(<30)$ (ref) & $1(7.1)$ & & & $8(57.1)$ & & \\
\hline Positive $(\geq 30)$ & $54(26.0)$ & 4.6 (0.6 to 35.7$)$ & 0.1484 & $128(61.5)$ & $1.2(0.4$ to 3.6$)$ & 0.7441 \\
\hline \multicolumn{7}{|l|}{ C3 baseline (mg/dL) } \\
\hline$\geq 90$ (ref) & $13(26.0)$ & & & $32(64.0)$ & & \\
\hline$<90$ & 41 (23.6) & 0.9 (0.4 to 1.8$)$ & 0.7227 & 106 (60.9) & $0.9(0.5$ to 1.7$)$ & 0.6931 \\
\hline \multicolumn{7}{|l|}{ C4 baseline (mg/dL) } \\
\hline$\geq 16$ (ref) & $12(17.1)$ & & & 45 (64.3) & & \\
\hline$<16$ & $41(26.8)$ & 1.8 (0.9 to 3.6$)$ & 0.1189 & $92(60.1)$ & $0.8(0.5$ to 1.5$)$ & 0.5543 \\
\hline \multicolumn{7}{|l|}{ UP/C baseline } \\
\hline$\leq 1$ (ref) & $7(21.2)$ & & & $23(69.7)$ & & \\
\hline$>1$ and $\leq 3$ & $24(27.3)$ & 1.4 (0.5 to 3.6$)$ & 0.4976 & $59(67.0)$ & $0.9(0.4$ to 2.1$)$ & 0.7812 \\
\hline$>3$ & $23(22.5)$ & 1.1 (0.4 to 2.8$)$ & 0.8725 & 54 (52.9) & $0.5(0.2$ to 1.1$)$ & 0.0945 \\
\hline \multicolumn{7}{|c|}{ Antimalarial treatment concomitantly during induction } \\
\hline Antimalarial (ref) & $18(21.4)$ & & & $56(66.7)$ & & \\
\hline No antimalarial & 37 (25.9) & $1.3(0.7$ to 2.4$)$ & 0.4510 & $82(57.3)$ & 0.7 (0.4 to 1.2$)$ & 0.1657 \\
\hline \multicolumn{7}{|c|}{ Lipid-modifying agent treatment concomitantly during induction } \\
\hline Statin (ref) & $14(26.9)$ & & & $33(63.5)$ & & \\
\hline No statin & $41(23.4)$ & $0.8(0.4$ to 1.7$)$ & 0.6059 & $105(60.0)$ & $0.9(0.5$ to 1.6$)$ & 0.6536 \\
\hline \multicolumn{7}{|l|}{ Induction treatment } \\
\hline MMF (ref) & $34(28.3)$ & & & $72(60.0)$ & & \\
\hline IVC & $21(19.6)$ & $0.6(0.3$ to 1.1$)$ & 0.1282 & $66(61.7)$ & $1.1(0.6$ to 1.8$)$ & 0.7956 \\
\hline $\begin{array}{l}\text { Percentages show the } \\
\text { Ref: reference category } \\
\text { ORs }>1 \text { imply more TF } \\
\text { Anti-dsDNA,, anti-doubl } \\
\text { mycophenolate mofetil; }\end{array}$ & $\begin{array}{l}\text { of TFs or } \\
\text { ete remissi } \\
\text { ed DNA; eC }\end{array}$ & $\begin{array}{l}\text { lete remitters with } \\
\text { comparison categ }\end{array}$ & pplicabl & $\begin{array}{l}\text { te category. } \\
\text { tegory. } \\
\text { travenous cyc }\end{array}$ & Iosphamide; MMF, & \\
\hline
\end{tabular}

anti-dsDNA (OR 2.9, 95\% CI 1.5 to 5.4, $\mathrm{p}=0.0012$ ). Among those in the maintenance population who did not have an early reduction in anti-dsDNA by week 8 , $30 \%$ developed TF during the maintenance phase compared with $10 \%$ of patients who did have an early reduction in anti-dsDNA (OR 3.5, 95\% CI 1.4 to 9.2, $\mathrm{p}=0.0097$ ). Lastly, in the maintenance population, positive anti-dsDNA at the end of induction was associated with TF. Among patients in the maintenance population who were anti-dsDNA positive at the end of induction, 26.9\% developed TF during the maintenance phase compared with $4.8 \%$ of patients who were anti-dsDNA 
Table 4 Significant covariates $(p<0.05)$ from the univariate analysis of early improvement (up to week 8 of induction) and end-of-induction parameters associated with renal outcome

\begin{tabular}{|c|c|c|c|c|c|c|c|c|}
\hline & \multicolumn{4}{|c|}{ Treatment failure } & \multicolumn{4}{|c|}{ Complete renal remission } \\
\hline & \multicolumn{2}{|l|}{$\mathrm{n}(\%)$} & \multirow[t]{2}{*}{ OR (95\% Cl) } & \multirow[t]{2}{*}{ p Value } & \multicolumn{2}{|l|}{$\mathrm{n}(\%)$} & \multirow[t]{2}{*}{ OR (95\% Cl) } & \multirow[t]{2}{*}{ p Value } \\
\hline \multicolumn{5}{|c|}{ Population: complete population $(n=370)$} & & & & \\
\hline \multicolumn{9}{|c|}{ UP/C reduction by week 8} \\
\hline $25 \%$ reduction (ref) & 63 & $(35.2)$ & & & & & & \\
\hline No $25 \%$ reduction & 66 & (59.5) & $2.7(1.7$ to 4.4$)$ & $<0.0001$ & & & & \\
\hline \multicolumn{9}{|c|}{ Anti-dsDNA reduction by week 8} \\
\hline Reduction (ref) & 19 & $(27.1)$ & & & & & & \\
\hline No reduction & 114 & $(50.4)$ & 2.7 (1.5 to 4.9$)$ & 0.0008 & & & & \\
\hline \multicolumn{9}{|c|}{ C3 normalisation by week 8} \\
\hline Normalisation (ref) & 27 & $(29.7)$ & & & & & & \\
\hline No normalisation & 109 & $(50.7)$ & $2.4(1.4$ to 4.1$)$ & 0.0008 & & & & \\
\hline \multicolumn{9}{|c|}{ C4 normalisation by week 8} \\
\hline Normalisation (ref) & 34 & (35.4) & & & & & & \\
\hline No normalisation & 101 & $(48.3)$ & $1.7(1.0$ to 2.8$)$ & 0.0359 & & & & \\
\hline \multicolumn{9}{|c|}{ C3 and C4 normalisation by week 8} \\
\hline Normalisation (ref) & 13 & $(25.5)$ & & & & & & \\
\hline No normalisation & 123 & $(48.2)$ & $2.7(1.4$ to 5.4$)$ & 0.0037 & & & & \\
\hline \multicolumn{9}{|c|}{ Population: maintenance population $(n=227)$} \\
\hline \multicolumn{9}{|c|}{ Anti-dsDNA reduction by week 8} \\
\hline Reduction (ref) & 6 & $(10.5)$ & & & & & & \\
\hline No reduction & 47 & (29.6) & $3.6(1.4$ to 8.9$)$ & 0.0063 & & & & \\
\hline \multicolumn{9}{|l|}{ C4 at end induction } \\
\hline$\geq 16$ (ref) & 31 & (19.9) & & & & & & \\
\hline$<16$ & 22 & (32.8) & $2.0(1.0$ to 3.8$)$ & 0.0388 & & & & \\
\hline \multicolumn{9}{|l|}{ UP/C at end induction } \\
\hline$\leq 1$ (ref) & & & & & 110 & (67.9) & & \\
\hline$>1$ & & & & & 26 & $(42.6)$ & $0.4(0.2$ to 0.6$)$ & 0.0007 \\
\hline \multicolumn{9}{|c|}{$\begin{array}{l}\text { Percentages show the proportion of TFs or complete remitters within the applicable covariate category. } \\
\text { Ref: reference category for ORs. } \\
\text { ORs }>1 \text { imply more TF or complete remission in comparison category than in reference category. } \\
\text { No covariates met the p<0.05 threshold for complete renal remission (complete population). } \\
\text { C3 (mg/dL) normalisation: change from }<90 \text { at baseline to } \geq 90 \text { at week } 8 \text {. } \\
\text { C4 (mg/dL) normalisation: change from }<16 \text { at baseline to } \geq 16 \text { at week } 8 \text {. } \\
\text { Anti-dsDNA (IU/mL) reduction: }>200 \text { at baseline to } \leq 60 \text { at week } 8 \text {. } \\
>30 \text { and } \leq 200 \text { at baseline to } \leq 30 \text { at week } 8 \text {. } \\
\text { The numbers are reduced due to missing data. Each of the significant covariates in the complete population analysis contained approximately } \\
300 \text { of the } 370 \text { patients. The maintenance population analysis has less missing data with approximately } 220 \text { patients of the } 227 \text { contributing to } \\
\text { the three analyses shown. } \\
\text { Anti-dsDNA, anti-double-stranded DNA; TF, treatment failure; UP/C, urine protein:creatinine ratio. }\end{array}$} \\
\hline
\end{tabular}

negative at the end of induction (OR 8.3, 95\% CI 1.0 to 66.0, $\mathrm{p}=0.0464)$.

\section{Changes in proteinuria}

Early changes in UP/C within 8 weeks and UP/C at the end of induction were independently associated with renal outcome (table 5). Among the complete population and the maintenance population, lack of reduction of UP/C by $\geq 25 \%$ within 8 weeks of induction was associated with TF. A total of $59 \%$ of patients in the complete population without UP/C reduction versus $35 \%$ with $\mathrm{UP} / \mathrm{C}$ reduction were $\mathrm{TFs}$ (OR 2.6, 95\% CI 1.5 to $4.4, \mathrm{p}=0.0006)$. A total of $33 \%$ of patients in the maintenance population without $\mathrm{UP} / \mathrm{C}$ reduction versus $21 \%$ with $\mathrm{UP} / \mathrm{C}$ reduction were TFs (OR 2.1, 95\% CI 1.0 to $4.2, \mathrm{p}=0.0471)$. Lastly, among patients in the maintenance population who entered the maintenance phase with UP/C of $>1,43 \%$ achieved complete renal remission. In contrast, $68 \%$ of patients with $\mathrm{UP} / \mathrm{C} \leq 1$ achieved complete renal remission (OR $0.3,95 \%$ CI 0.2 to $0.6, \mathrm{p}=0.0008$ ).

\section{Changes in complement levels}

While changes in complement levels during induction were not independently associated with clinical outcomes during maintenance $(p>0.05)$, a number of these measures did demonstrate association in the univariate analysis (table 4). C3 and C4 normalisation by week 8 (both individually and combined as a single measure of normalisation) showed association with TF in the complete population. Depending on the complement measure, patients who did not normalise complement had between 1.7 and 2.7 times the odds of TF compared with patients who did normalise complement. A similar magnitude of effect was seen in the analysis of the maintenance population for $\mathrm{C} 4$ level at the end of induction. 
Table 5 Multivariate analysis of baseline and early improvement parameters as predictors of renal outcome

\begin{tabular}{|c|c|c|c|}
\hline Analysis covariate & Comparison & OR $(95 \% \mathrm{Cl})$ & p Value \\
\hline \multicolumn{4}{|l|}{ Population: complete population $(n=370)$} \\
\hline \multicolumn{4}{|l|}{ TF } \\
\hline Anti-dsDNA at baseline & Positive $(\geq 30)$ vs negative $(<30)$ & $12.7(1.6$ to 101$)$ & 0.0167 \\
\hline UP/C reduction by week 8 & No $25 \%$ reduction vs $25 \%$ reduction & 2.6 (1.5 to 4.4$)$ & 0.0006 \\
\hline Anti-dsDNA reduction by week 8 & No reduction vs reduction & 2.9 (1.5 to 5.4$)$ & 0.0012 \\
\hline C3 normalisation by week 8 & No normalisation vs normalisation & 1.7 (0.9 to 3.1$)$ & 0.0766 \\
\hline \multicolumn{4}{|l|}{ Complete renal remission } \\
\hline Ethnicity & Non-Hispanic vs Hispanic & 2.0 (1.2 to 3.3$)$ & 0.0061 \\
\hline C4 normalisation by week 8 & No normalisation vs normalisation & $0.6(0.4$ to 1.1$)$ & 0.0794 \\
\hline \multicolumn{4}{|c|}{ Population: maintenance population $(n=227)$} \\
\hline \multicolumn{4}{|l|}{ TF } \\
\hline Induction treatment & IVC vs MMF & $0.5(0.2$ to 1.0$)$ & 0.0500 \\
\hline Antimalarial treatment & No treatment vs treatment & $2.4(1.1$ to 5.1$)$ & 0.0209 \\
\hline UP/C reduction by week 8 & No $25 \%$ reduction vs $25 \%$ reduction & 2.1 (1.0 to 4.2$)$ & 0.0471 \\
\hline Anti-dsDNA reduction by week 8 & No reduction vs reduction & 3.5 (1.4 to 9.2$)$ & 0.0097 \\
\hline Anti-dsDNA at end of induction & Positive ( $\geq 30)$ vs negative $(<30)$ & $8.3(1.0$ to 66.0$)$ & 0.0464 \\
\hline \multicolumn{4}{|l|}{ Complete renal remission } \\
\hline \multirow[t]{3}{*}{ Age group* } & $>20$ and $\leq 30$ vs $\leq 20$ & 0.7 (0.3 to 1.8$)$ & 0.4801 \\
\hline & $>30$ and $\leq 40$ vs $\leq 20$ & $1.8(0.7$ to 4.5$)$ & 0.2303 \\
\hline & $>40$ vs $\leq 20$ & 2.7 (0.9 to 8.3$)$ & 0.0804 \\
\hline eGFR at baseline & $\geq 90$ vs $<90$ & 2.0 (1.0 to 3.8$)$ & 0.0407 \\
\hline UP/C at end induction & $>1$ vs $\leq 1$ & $0.3(0.2$ to 0.6$)$ & 0.0008 \\
\hline
\end{tabular}

TF: ORs $>1$ imply more failure in first factor level of comparison.

Complete renal remission: ORs $>1$ imply more remission in first factor level of comparison.

C3 (mg/dL) normalisation: change from $<90$ at baseline to $\geq 90$ at week 8 .

$\mathrm{C} 4$ (mg/dL) normalisation: change from $<16$ at baseline to $\geq 16$ at week 8 .

Anti-dsDNA (IU/mL) reduction: $>200$ at baseline to $\leq 60$ at week 8 .

$>30$ and $\leq 200$ at baseline to $\leq 30$ at week 8 .

*Overall $p$ value for age: $p=0.0279$.

Anti-dsDNA, anti-double-stranded DNA; eGFR, estimated glomerular filtration rate; IVC, intravenous cyclophosphamide; MMF, mycophenolate mofetil; TF, treatment failure; UP/C, urine protein:creatinine ratio.

A total of $33 \%$ of patients with $\mathrm{C} 4<16 \mathrm{mg} / \mathrm{dL}$ versus $20 \%$ of patients with $\mathrm{C} 4 \geq 16 \mathrm{mg} / \mathrm{dL}$ at the end of induction were TFs during maintenance (OR 2.0, 95\% CI 1.0 to $3.8, \mathrm{p}=0.0388$ ) (table 4$)$.

\section{DISCUSSION}

In this study, we analysed data from the ALMS of IVC versus MMF for induction treatment followed by MMF versus AZA for maintenance treatment of lupus nephritis. Our objectives were twofold: (1) to determine if baseline factors present at the beginning of induction were associated with renal outcome and (2) to determine if changes in biological factors in the early weeks of induction or by the end of induction were associated with renal outcome during a 36-month maintenance period. We studied the complete intent-to-treat population (complete population) as well as the population of patients who continued into the maintenance phase after having achieved a complete or partial renal response after induction treatment (maintenance population). It is important to note that patients who did not respond to the induction treatment regimen were not randomised into the maintenance phase. Thus, the patients in the maintenance phase were inherently different from those who started the trial in the induction phase. In order to mitigate this potential source of bias, we chose to analyse the complete population and the maintenance population separately and report the results for both populations. For purposes of the analysis, we made the conservative decision that those patients who were not randomised into the maintenance phase were assumed to have a treatment outcome of either TF or non-complete remission, as appropriate.

In the multivariate analysis of the complete population, only non-Hispanic ethnicity was independently associated with complete remission during the maintenance phase. Three factors were independently associated with TF: (1) anti-dsDNA positivity at baseline, (2) failure to reduce anti-dsDNA within 8 weeks of induction and (3) failure to reduce $\mathrm{UP} / \mathrm{C}$ by at least $25 \%$ within 8 weeks of induction.

In the multivariate analysis of those patients who continued into the maintenance phase of the trial (the maintenance population), baseline eGFR $\geq 90 \mathrm{~mL} / \mathrm{min} / 1.73 \mathrm{~m}^{2}$ and $\mathrm{UP} / \mathrm{C} \leq 1$ at the end of induction were independently associated with complete remission during the maintenance phase. Induction treatment with IVC was associated with a lower likelihood of TF, while lack of treatment with antimalarials, failure to reduce anti-dsDNA or UP/C within 8 weeks of induction, and positive anti-dsDNA at the end of induction were independently associated with TF. 
Our current findings build upon those from our previous study in which we found that early reduction in proteinuria and early normalisation of complement were independently associated with renal response at 6 months. ${ }^{2}$ Consistent with our previous findings, we have now shown that early improvement in proteinuria is independently associated with renal outcome during the 36-month maintenance phase following completion of induction therapy. Differing from our previous study, we found that early changes in complement levels were not independently associated with long-term renal outcome. Although we previously found that early reduction in anti-dsDNA was not predictive of response at 6 months, our current study demonstrates that changes in anti-dsDNA during induction are predictive of response during the longer maintenance phase. Given our extended period of observation out to 36 months after the completion of induction, it is not surprising that some of our results differ from our previous shorterterm study. It is well described and currently accepted that response to treatment of lupus nephritis continues to occur well beyond induction therapy. Thus, it is often difficult to draw a clear distinction between when induction treatment ends and maintenance treatment begins. For example, one study suggested that the median time to renal response with intravenous Cytoxan was 10 months. ${ }^{6}$ A study of oral Cytoxan for induction treatment of lupus nephritis followed by MMF or AZA as maintenance therapy demonstrated that improvement in proteinuria and renal function continues well into the maintenance phase. ${ }^{7}$ These observations highlight both the importance of long-term follow-up when assessing renal response to treatment in lupus nephritis trials and the somewhat arbitrary nature of our current definitions of disease response.

Our findings demonstrating a higher likelihood of renal remission in patients of non-Hispanic ethnicity in the complete population expand upon previous studies that have shown a greater incidence and worse prognosis in patients of Hispanic ethnicity with lupus nephritis. ${ }^{8} 9$ Our data showing a reduced likelihood of TF in patients in the maintenance population treated with antimalarials are consistent with the results of a study of patients with MMF-treated membranous lupus nephritis in which patients who received concomitant treatment with hydroxychloroquine were more likely to achieve renal remission by 12 months as compared with patients who did not receive hydroxychloroquine. ${ }^{10}$ These results are consistent with a broader accumulating literature demonstrating the many benefits of treatment with antimalarials, including the reduction of flares and prevention of renal damage. ${ }^{11}{ }^{12}$ Although ALMS showed similar efficacy of IVC and MMF, inducing a renal response at 6 months, our current study suggests that patients treated with IVC during induction are less likely to develop TF during maintenance. A similar observation was made in a subgroup analysis of the ALMS maintenance phase, in which there was a trend of reduced incidence of TF during maintenance in those patients who received IVC as the induction agent. This trend of improved efficacy with IVC was present in patients regardless of whether they received MMF or AZA during maintenance. ${ }^{5}$ In our present analysis, the magnitude of the difference in response between the IVC and MMF groups is not profound enough to currently dictate individual patient treatment decisions. It is also important to recognise that various factors play a role in the choice of an induction agent for a particular patient, including the documented and perceived risks of a potential medication. However, these observations emphasise the importance of long-term renal outcome data in assessing the efficacy of induction regimens for the treatment of lupus nephritis.

Several other studies have examined predictors of renal response to treatment. Consistent with our findings, an early response to treatment as defined by proteinuria has been shown to be associated with improved long-term patient and renal survival. An analysis of 90 patients from the Euro-Lupus Nephritis Trial of low-dose IVC versus high-dose IVC for the induction treatment of lupus nephritis demonstrated that a decrease in serum creatinine and proteinuria of $<1 \mathrm{~g}$ at 6 months predicted a favourable renal outcome at 10 years. ${ }^{13}$ Another study of 85 patients showed that change in proteinuria at 1 year was predictive of long-term renal survival and overall mortality. ${ }^{14}$

A strength of our study is that we used data from ALMS, a randomised controlled trial that collected data throughout a 36-month maintenance phase following a 6-month induction phase. ALMS is one of the largest controlled trials for the treatment of lupus nephritis. By including data from the 36-month maintenance phase, we expanded upon our previous manuscript using only the 6-month induction phase data. Similar to our previous manuscript, a limitation of our current study is the fact that it is a post hoc analysis.

In conclusion, using long-term data from the ALMS, we identified several factors during the induction phase that are associated with renal outcome during the maintenance phase. Because of the differing patient composition of the complete and maintenance populations, we analysed the two populations separately. The maintenance population was composed of only those patients who achieved a renal response at the end of the induction phase of the trial and continued into the maintenance phase of the trial. The data from both populations are presented separately in this manuscript.

Although our findings contribute to the understanding of predictors of renal outcome in lupus nephritis, we believe that the associations described in this study are not strong enough to directly impact therapeutic decision making in individual patients in the clinic. Better biomarkers are needed to achieve this important goal. Lastly, in future controlled trials of lupus nephritis, studying the factors identified in our present analysis in a prespecified fashion might serve to further elucidate their association with renal response to treatment. 
Acknowledgements We acknowledge the investigators and patients who participated in the Aspreva Lupus Management Study.

Contributors Each of the authors contributed to the analysis, writing, review and final approval of this manuscript.

Funding This work was supported in part by the Rosalind Russell Medical Research Center for Arthritis at the University of California, San Francisco. The Aspreva Lupus Management Study was sponsored by Vifor. VL is an employee of Vifor, and NS was a former employee of Vifor.

Competing interests None declared.

Provenance and peer review Not commissioned; externally peer reviewed.

Data sharing statement No additional data are available.

Open Access This is an Open Access article distributed in accordance with the Creative Commons Attribution Non Commercial (CC BY-NC 4.0) license, which permits others to distribute, remix, adapt, build upon this work noncommercially, and license their derivative works on different terms, provided the original work is properly cited and the use is non-commercial. See: http:// creativecommons.org/licenses/by-nc/4.0/

\section{REFERENCES}

1. Faurschou M, Dreyer L, Kamper A, et al. Long-term mortality and renal outcome in a cohort of 100 patients with lupus nephritis. Arthritis Care Res 2010;62:873-80.

2. Dall'Era M, Stone D, Levesque V, et al. Identification of biomarkers that predict response to treatment of lupus nephritis with mycophenolate mofetil or pulse cyclophosphamide. Arthritis Care Res 2011;63:351-7.

3. Appel GB, Contreras G, Dooley MA, et al. Mycophenolate mofetil versus cyclophosphamide for the induction treatment of lupus nephritis. J Am Soc Nephrol 2009;49:128-40.
4. Sinclair A, Appel G, Dooley MA, et al. Mycophenolate mofetil as induction and maintenance therapy for lupus nephritis: rationale and protocol for the randomized, controlled Aspreva Lupus Management Study (ALMS). Lupus 2007;16:972-80.

5. Dooley MA, Jayne D, Ginzler EM, et al. Mycophenolate versus azathioprine as maintenance therapy for lupus nephritis. $N$ Engl J Med 2011:365:1186-95.

6. Ioannides JP, Boki KA, Katsorida ME, et al. Remission, relapse, and re-remission of proliferative lupus nephritis treated with cyclophosphamide. Kidney Int 2000;57:258-64.

7. McKinley A, Park E, Spetie D, et al. Oral cyclophosphamide for lupus glomerulonephritis: an underused therapeutic option. Clin J Am Soc Nephrol 2009;4:1754-60.

8. Alarcon GS. Multiethnic lupus cohorts: what have they taught us? Rheumatol Clin 2011;7:3-6.

9. Burgos PI, McGwin G, Pons-Estel GJ, et al. US patients of Hispanic and African ancestry develop lupus nephritis early in the disease course: data from LUMINA, a multiethnic US cohort. Ann Rheum Dis 2011;70:393-4.

10. Kasitanon N, Fine DM, Haas M, et al. Hydroxychloroquine use predicts complete renal remission within 12 months among patients treated with mycophenolate mofetil therapy for membranous lupus nephritis. Lupus 2006;15:366-70.

11. Akhavan PS, Su J, Lou W, et al. The early protective effect of hydroxychloroquine on the risk of cumulative damage in patients with systemic lupus erythematosus. J Rheumatol 2013;40: 831-41.

12. Pons-Estel GJ, Alarcon GS, McGwin G, et al. Protective effect of hydroxychloroquine on renal damage in patients with lupus nephritis: data from a multiethnic US cohort. Arthritis Rheum 2009;61:830-9.

13. Houssiau FA, Vasconcelos C, D'Cruz D, et al. The 10-year follow-up data of the Euro-Lupus Nephritis Trial comparing low-dose and high-dose intravenous cyclophosphamide. Ann Rheum Dis 2010;69:61-4.

14. Fraenkel L, Mackenzie T, Joseph L, et al. Response to treatment as a predictor of longterm outcome in patients with lupus nephritis. J Rheumatol 1994;21:2052-7. 